\title{
Transmission, Perinatal Infection
}

National Cancer Institute

\section{Source}

National Cancer Institute. Transmission, Perinatal Infection. NCI Thesaurus. Code C19084.

Passage or transfer, as of a disease, to a recipient unborn offspring in utero. $(\mathrm{NCl})$ 